\title{
Human Nerve Growth Factor Improves Spatial Memory in Aged but Not in Young Rats
}

\author{
Alicja L. Markowska, ${ }^{1}$ Vassilis E. Koliatsos, ${ }^{2}$ Steven J. Breckler, ${ }^{1}$ Donald L. Price, ${ }^{2}$ and David S. Olton ${ }^{1}$ \\ ${ }^{1}$ Neuromnemonics Laboratory, Department of Psychology, The Johns Hopkins University, Baltimore, Maryland 21218-2686 \\ and 'Departments of Pathology, Neurology, and Neuroscience, Neuropathology Laboratory, The Johns Hopkins \\ University, School of Medicine, Baltimore, Maryland 21205
}

\begin{abstract}
The behavioral effects of human nerve growth factor (NGF) were assessed in Fischer-344 rats of two ages: 4 months old (4MO) and 23 months old (23MO). Recent memory was tested in delayed alternation ( $T$ maze), reference memory in a place discrimination (water maze), and sensorimotor skills in a battery of sensorimotor tasks. Each rat was preoperatively trained in each task, given either a control procedure (CON), or continuous infusion of human NGF via an osmotic minipump, and retested again 3 weeks later. Two doses of NGF were delivered: $40 \mu \mathrm{g}$ and $160 \mu \mathrm{g}$ (total amount infused over a period of 4 weeks). In 23MO-NGF rats, both doses improved performance in the recent memory task, and in some measures of the place learning task, but had no effect on sensorimotor skills. In 4MO-NGF rats, the low dose impaired performance in the recent memory task, but not in the place discrimination or in the sensorimotor tasks. These data indicate that human NGF can reverse age-related cognitive impairments in old rats. However, the present study also raises the issue of potential detrimental effects that NGF may exert in young normal subjects.
\end{abstract}

[Key words: neurotrophins, NGF, place discrimination, recent memory, sensorimotor skills, spatial memory, aging]

Aged rats are impaired in several cognitive functions, including spatial recent memory (Ingram et al., 1981; deToledo-Morell et al., 1988; Aggleton et al., 1989) and place discrimination (Gage et al., 1984, 1988b; Rapp et al., 1987; Gallagher and Pelleymounter, 1988; Fischer et al., 1991b). As indicated by the results of experiments with lesions and drugs (Mitchell et al., 1982; Morris et al., 1982; Decker and Gallagher, 1987; Givens and Olton, 1990; Markowska et al., 1991; Olton et al., 1991a,b; Olton and Markowska, 1992), both of these cognitive functions depend on the integrity of the basal forebrain cholinergic system (BFCS), a collection of large cholinergic neurons in the medial septum, substantia innominata, and globus pallidus. Neurons in the BFCS change with age, and these age-associated changes are correlated with cognitive impairments. In Alzheimer's dis-

\footnotetext{
Received Aug. 26, 1993; revised Jan. 6, 1994; accepted Feb. 8, 1994.

This research was supported by Program Project Grant P50 AG 05146 to D.L.P We thank K. Morrione, K. Pang, and M. L. Voytko for helpful comments on earlier versions of the manuscript, and M. Barra, R. Henshaw, M. Markowska, $S$. Sinko, and $Y$. Tomozawa for assistance in behavioral testing and analyzing the data. V.E.K. and D.L.P. are the recipients of a Leadership and Excellence in Alzheimer's Disease (LEAD) award (NIA AG-07914).

Correspondence should be addressed to Alicja L. Markowska, Ph.D., at the above address.
}

Copyright (C) 1994 Society for Neuroscience $0270-6474 / 94 / 144815-10 \$ 05.00 / 0$ ease, presynaptic cholinergic markers are reduced in the cortical targets of the BFCS (for review, see Price, 1986; Olton, 1990; Dekker ct al., 1991). In aged rodents, these neurons undergo degenerative changes (Biegon et al., 1986; Fischer et al., 1987, 1989, 199 la,b; Gilad et al., 1987; Altavista et al., 1988, 1990; Gomez-Pinilla et al., 1989), and their dysfunction has been linked to impaired learning and memory (Bartus et al., 1980, 1982; Ingram et al., 1981; Biegon et al., 1986; Gallagher and Pelleymounter, 1988; Koh and Loy, 1988; Koh et al., 1989; Luine and Hearns, 1990).

Nerve growth factor (NGF) can alter the biological function of BFCS neurons. This peptide promotes the differentiation of BFCS neurons (Gnahn et al., 1983; Mobley et al., 1986) and ameliorates lesion-induced retrograde abnormalities in these cells during the first few weeks after axotomy (Hefti, 1986; Williams et al., 1986; Kromer, 1987; Gage et al., 1988a; Tuszynski et al., 1990; Koliatsos et al., 1991). Although reductions in the immunoreactivity of the low-affinity NGF receptor in various forebrain nuclci are correlated with impairments of spatial memory (Fischer et al., 1987, 1989; Koh et al., 1989), NGF in the target areas of the BFCS does not show age-related reductions (Hellweg et al., 1990; Crutcher and Weingartner, 1991). Still, pathology in cholinergic axons may reduce the availability of NGF to targets of aged BFCS neurons, and aged cholinergic neurons may be less responsive to NGF. Therefore, despite the lack of evidence for a specific deficit of NGF in aged brains, stimulation of BFCS neurons in aged animals remains a viable option to influence cognitive functions that depend on the cholinergic system.

The behavioral effectiveness of NGF therapy has been assessed in young rats following experimental brain damage (Will and Hefti, 1985; Mandel et al., 1989; Dekker et al., 1992) and in aged rats with age-related cognitive impairments. NGF ameliorated age-related spatial memory impairments in place discrimination tested in the water maze in 30 -month-old rats with obvious pathological changes in BFCS neurons, and in behaviorally impaired 18-month-old rats where measurable cholinergic cellular atrophy was not present (Fischer et al., 1987, 1991a). In contrast, NGF failed to improve brightness discrimination (Williams at al., 1991), and had inconsistent effects on measures that might reflect sensorimotor performance (Fischer et al., 1991a; Williams et al., 1991).

The present study was designed to assess in a comprehensive fashion the effects of NGF on memory in old (23 month) and young ( 4 month) rats. The data from young rats addresses the question of whether the effects of NGF differ as a function of age. The inclusion of three different behavioral tests provides 
new information about the domain of behaviors affected by NGF and helps in the interpretation of the behavioral effects that do occur. Recent memory was assessed by spatial delayed alternation in a $\mathrm{T}$ maze. Reference memory was assessed by place discrimination in the water maze using the variable interval (VI) probe test, a new procedure that provides a more sensitive and useful measurement of spatial memory than the traditional procedures (Markowska et al., 1993). Both tasks are sensitive to disruption of the septohippocampal cholinergic system by lesions, pharmacological treatment, and aging (Wenk et al., 1989; Givens and Olton, 1990; Markowska el al., 1990a,b). Sensorimotor performance was assessed because no data are available from a systematic series of tests to determine if NGF alters sensorimotor skills, and this information can help interpret the expected beneficial effects of NGF on the cognitive tasks. If NGF does not alter sensorimotor skills, then changes in performance in the cognitive tasks are likely to be due to improved memory rather than to nonmnemonic aspects of behavior. Human, rather than mouse, NGF was used to determine if this type of NGF can reduce age-related impairments in place discrimination as mouse NGF did in previous experiments (Fischer et al., 1987, 1991a). Two different doses were used, to determine the effective range of doses and the dose dependency of the effects. Neuronal changes in the BFCS of those rats, which may mediate, at least in part, behavioral effects of human NGF, are described elsewhere (Fleischman et al., 1992).

\section{Materials and Methods}

\section{Subjects}

Male Fischer-344 rats $(N=42), 4$ months old ( $4 \mathrm{MO})$ or 23 months old $(23 \mathrm{MO})$ at the time of surgery, were maintained in a colony room with a $12 / 12 \mathrm{hr}$ light/dark cycle with lights on at $7 \mathrm{~A} . \mathrm{M}$. Food was available ad libitum in the home cage. Water was available ad libitum except during testing of delayed alternation, when sufficient water was provided at the end of each day's test session to maintain the body weight at 80$85 \%$ of ad libitum weight.

Behavioral testing took place during the light cycle. Each of five groups of rats is identified by an abbreviation describing the age (4MO, 23MO), type of infusion (CON, NGF), and the dose of human NGF (40 $\mu \mathrm{g}, 160$ $\mu \mathrm{g})$ where appropriate. The number of rats in each group is in parentheses: 4MO-CON (9), 4MO-NGF40 (8), 23MO-CON (9), 23MONGF40 (10), and 23MO-NGF160 (6).

The order and duration of the tests are summarized in Table 1.

\section{Surgery}

Rats were anesthetized with a mixture of $33 \% \mathrm{O}_{2}, 66 \% \mathrm{~N}_{2} \mathrm{O}_{2}$, and $1-$ $2 \%$ ethrane (Gorman et al., in press). Gases were delivered through a nose mask attached to a Kopf stereotaxic instrument. To prevent infection, chloramphenicol $(30 \mathrm{mg} / \mathrm{kg}$, i.p.) was given with half of the dose delivered before surgery and half immediately after surgery. In sterile conditions (Montero and Hefti, 1988), a burr hole was made $1 \mathrm{~mm}$ posterior to bregma and $1.5 \mathrm{~mm}$ lateral to midline. A 28 gauge stainless steel cannula was lowered stereotaxically to the right or left lateral ventricle. The cannula was connected to an Alzet 2002 osmotic minipump (Alza Corporation, Palo Alto, CA) via Silastic tubing. The pump was filled with either human recombinant NGF (Genentech, Inc., San Francisco, CA; courtesy of Dr. Louis E. Burton) or vehicle solution $(210 \mu 1$ per pump) and was placed in a subcutaneous pocket in the neck region. The vehicle was artificial cerebrospinal fluid (122.5 mM NaCl, 25.2 mM $\mathrm{NaHCO}_{3}, 5.4 \mathrm{~mm} \mathrm{KCl}, 2.0 \mathrm{~mm} \mathrm{MgSO}_{4}, 1.2 \mathrm{~mm} \mathrm{NaH}, \mathrm{PO}_{4}, 2.0 \mathrm{~mm}$ $\mathrm{CaCl}_{2}, 10 \mathrm{~mm}$ glucose, $\mathrm{pH} 7.4$ ) containing $100 \mu \mathrm{g} / \mathrm{ml}$ rat serum albumin. Human recombinant NGF was kept in solution in $0.2 \%$ glacial acetic acid. Following lyophilization, NGF was resuspended in $10 \mu \mathrm{l}$ of $0.5 \%$ acetic acid and then buffered with $200 \mu$ of vehicle solution. The amount of human NGF per pump was either $20 \mu \mathrm{g}$ or $80 \mu \mathrm{g}$. After $14 \mathrm{~d}$, the pump was replaced with a new one filled with the same solution. The procedures for anesthesia and sterile conditions were the same as those used previously.

In the 4MO-CON group, four rats received vehicle treatment and the other four received sham operation. In the $23 \mathrm{MO}-\mathrm{CON}$ group, seven rats received vehicle treatment and the remaining two received sham operation.

\section{Spatial alternation in a $T$ maze}

Apparatus. The floor of the T maze was constructed of wood $(10 \mathrm{~cm}$ wide). The start arm ( $58 \mathrm{~cm}$ long) had a guillotine door $(18 \mathrm{~cm}$ from the end) that separated it into a starting platform (18 cm long) and a stem $(40 \mathrm{~cm}$ long). Each goal arm $(37 \mathrm{~cm}$ long) had a cup for water (1 $\mathrm{cm}$ in diameter, $3 \mathrm{~cm}$ from the end). An edge $(1 \mathrm{~cm}$ high) was on the side of every arm and the stem. The maze was located in a large room with many extramaze cues.

Shaping. Shaping took place for 3-4 d to train each rat to run to the end of the arm and drink the water. During the first day, water was placed in many cups spread throughout the maze. Each rat was placed on the maze for 10 min to explore the maze and drink the water. During each successive day, the number of water cups was reduced and they were placed closer to the ends of each arm. At the end of shaping, water was present only in the cup at the end of each arm.

Training. For each trial, a few drops of water were placed in the cup at the end of one arm. For the first forced trial, the arm containing water was chosen pseudorandomly, with the constraint that the same arm was not chosen more than two consecutive days. A block of wood was placed at the entrance to the other arm. The rat was placed on the starting platform, the guillotine door was raised, and the rat was allowed to go to the available arm and drink the water.

For each subsequent choice trial, water was placed in the arm not entered by the rat on the previous trial. The rat was placed on the starting platform, the guillotine door was raised, and the rat was allowed to choose one arm. If the arm had water, the rat was allowed to drink it, and a correct response was recorded. If the arm did not have water, the rat was removed immediately, and an incorrect resporse was recorded. Consequently, the optimal strategy for the rat on each choice trial was to remember the arm entered during the previous trial and to choose the opposite arm. Each session had one forced trial and 20 choice trials. One session was given per day. The intertrial interval was $30 \mathrm{sec}$. Choice accuracy for choice trials was the percentage of correct responses in the 20 trials of each session.

\section{Place discrimination in the water maze}

Apparatus. The tank was $180 \mathrm{~cm}$ in diameter and $60 \mathrm{~cm}$ high. It was filled to a depth of $35 \mathrm{~cm}$ with water maintained at $24^{\circ} \mathrm{C}\left( \pm 1^{\circ}\right)$ by an aquarium heater. White nontoxic watercolor paint was added to the water to make it opaque. The inside of the tank was painted white. A moveable platform $(10 \mathrm{~cm} \times 10 \mathrm{~cm})$ was located $40 \mathrm{~cm}$ from the cdgc of the tank. In its raised position, the top of the platform was $1 \mathrm{~cm}$ below the surface of the water so that the rat could climb on it to escape from the water. In its lowered position, the top of the platform was at the bottom of the tank and not available to the rat.

The tank was divided into four quadrants (NE, NW, SE, SW) by two imaginary perpendicular lines crossing in the center of the tank. A tracking system (HVS Image Analysis VP-112, England) was used to record the data. A camera was mounted $1.4 \mathrm{~m}$ above the surface of the water, and was connected to a microprocessor. Illumination was provided by four $40 \mathrm{~W}$ light bulbs mounted equidistantly, $1.2 \mathrm{~m}$ above the surface of the water. The tank was located at one end of a small rectangular room with a variety of visual cues, distal (on the wall) and proximal (on the rim of the tank).

For shaping in the straight swim (sce below), two picces of transparent plastic, $100 \mathrm{~cm}$ long and $60 \mathrm{~cm}$ high, were placed parallel to each other to form an alley $15 \mathrm{~cm}$ wide, with walls $25 \mathrm{~cm}$ above the surface of the water. One end of the alley was against the edge of the tank.

Shaping in the straight swim. Each rat was trained to swim in the water and climb on the escape platform. The raised platform was placed at the end of the alley. Black curtains around the tank eliminated the visual cues that were used for the subsequent place discrimination. No spatial discrimination was required because the alley was sufficiently narrow that the rat had to encounter the escape platform at the end.

For each trial, the rat was placed at the edge of the tank and allowed to swim to the platform. After reaching the platform, the rat was allowed to rest on it for $10 \mathrm{sec}$. The intertrial interval was $3 \mathrm{~min}$. Five trials 
Table 1. Time table

\begin{tabular}{|c|c|c|c|c|c|c|c|c|c|c|}
\hline & \multicolumn{5}{|c|}{ Preoperative testing } & \multicolumn{2}{|c|}{ Surgery } & \multicolumn{3}{|c|}{ Postoperative testing } \\
\hline & $\begin{array}{l}\text { Hand- } \\
\text { ling }\end{array}$ & $\begin{array}{l}\text { Spatial } \\
\text { alter. }\end{array}$ & $\begin{array}{l}\text { Sens. } \\
\text { mot. }\end{array}$ & $\begin{array}{l}\text { Str. } \\
\text { swim }\end{array}$ & $\begin{array}{l}\text { Place } \\
\text { disc. }\end{array}$ & $\begin{array}{l}\text { First } \\
\text { pump }\end{array}$ & $\begin{array}{l}\text { Second } \\
\text { pump }\end{array}$ & $\begin{array}{l}\text { Spatial } \\
\text { alter. }\end{array}$ & $\begin{array}{l}\text { Sens. } \\
\text { mot. }\end{array}$ & $\begin{array}{l}\text { Place } \\
\text { disc. }\end{array}$ \\
\hline Calendar days & $1-4$ & $5-21$ & $22-25$ & $26-27$ & $28-30$ & $1-2$ & $15-16$ & $21-24$ & 26 & $27-30$ \\
\hline \# of sessions & 3 & 10 & 3 & 2 & 3 & & & 4 & 1 & 4 \\
\hline
\end{tabular}

were given per session. The trial terminated when the rat found the platform, or in $60 \mathrm{sec}$. Two sessions were given cach day for 2 consecutive days, with an intersession interval of approximately $2 \mathrm{hr}$. Each rat was monitored throughout testing for signs of hypothermia.

Place discrimination. For the place discrimination, the platform was placed in one location in the tank ( $40 \mathrm{~cm}$ from the edge), constant during all testing. Each session had five platform trials and one variable interval (VI) probe trial (Markowska et al., 1993), both of which are described subsequently.

For each platform trial, the platform was placed in the same location $(40 \mathrm{~cm}$ from the edge of the tank) in the raised position with its top 1 $\mathrm{cm}$ below the surface of the water. The three quadrants not containing the escape platform were used for the starting locations. For each trial, one of the three start locations was chosen in a counterbalanced sequence so that each location was used once in each successive block of three trials. The trial terminated when the rat found the platform, or in 60 $\mathrm{sec}$, whichever came first. If the rat did not find the platform in $60 \mathrm{sec}$, the experimenter led him there and let him stand on it for $10 \mathrm{sec}$. After completion of the trial, the rat was placed in a holding cage for an intertrial interval of 3-4 min. For each VI probe trial, the platform was in its lowered position at the start of the trial. After a variable interval $(10-40 \mathrm{sec})$, the platform was raised so the rat could climb on it. For platform trials, three measures of performance were obtained: Swim time was the time between leaving the start location and climbing onto the escape platform. Swim distance was the distance swum, in centimeters, from the start location to the escape platform. Heading angle was the deviation between the actual direction of the rat when leaving the edge of the tank and a straight line from the start location to the escape platform. Lower scores in all three measures indicate better performance.

For the VI probe trials, three measures of performance were obtained: Quadrant time was the percentage of time spent in the quadrant with the escape platform. Annulus-40 time was a similar measure for the percentage of time spent in a circle with a diameter of $40 \mathrm{~cm}$, centered where the center of the escape platform had been on the platform trials. Platform crossings were the number of crossings over the escape platform location. Higher scores indicate better performance in all three measures.

\section{Sensorimotor tests}

Sensorimotor tests were used to assess coordinated behaviors, orienting reactions, forelimb weakness, postural abnormalities, climbing, and locomotion. Each test was given once a day for three consecutive days prior to surgery and for $1 \mathrm{~d}$ after surgery, with a maximum of $120 \mathrm{sec}$ for each test during each day.

Walking initiation. The rat was placed on a table, and the time for the rat to move one body length was recorded.
Turning in an alley. The rat was placed facing the back wall of an alley $(6 \mathrm{~cm}$ wide with walls $30 \mathrm{~cm}$ high). The time taken by the rat to turn around to face the open end of the alley was recorded.

Turning on an inclined screen. The rat was placed on the center of a horizontal wire mesh screen, approximately $35 \mathrm{~cm}$ square, and $60 \mathrm{~cm}$ above the table. The screen was inclined to $45^{\circ}$ with the rat facing downward. The time taken by the rat to turn to face upward was recorded.

Wire suspension. The rat was placed to hang by its front paws on a horizontal wire, approximately $60 \mathrm{~cm}$ above a foam cushion on the table. The time until the rat fell from the wire was recorded.

Bridges. Each bridge was a wooden plank or dowel $(60 \mathrm{~cm}$ long) suspended between two platforms, $60 \mathrm{~cm}$ above a foam cushion. Each rat was placed in the middle of the bridge. If the rat reached a platform within $2 \mathrm{~min}$, the latency to reach the platform was the time in seconds taken to reach the platform, and the latency to fall was $120 \mathrm{sec}$. If the rat fell, the latency to fall was the time in seconds until the rat fell, and the latency to reach the platform was $120 \mathrm{sec}$.

The flat bridges were wooden planks of three different widths: 2,4 , and $6 \mathrm{~cm}$. The round bridge was a dowel, $2 \mathrm{~cm}$ in diameter.

\section{Data analysis}

For spatial alternation, the data are presented as the mean choice accuracy for each block of 20 trials (the percentage of correct responses in 20 successive choices) \pm the standard error of the mean (SEM). For analyses of variance (ANOVA) assessing preoperative acquisition, the data were taken from sessions 1-10. For ANOVA comparing preoperative and postoperative performance, the data were taken from sessions $7-10$ of preoperative training and from sessions $1-4$ of postoperative training.

The effect of human NGF on spatial alternation was assessed with a within-subjects analysis of preoperative and postoperative performance. The preoperative baseline was the mean of the last four preoperative sessions (sessions 7-10). Postoperative performance was the mean of all postopcrative scssions (scssions 1-4). A comparison of postoperative performance to preoperative performance placed each rat into one of three categories based on the difference between mean postoperative performance and mean preoperative performance: improved (better than 2 SEMs), unchanged (within 2 SEMs), or impaired (worse than 2 SEMs).

For the place discrimination, the data are presented as a mean \pm SEM in each session for each of the six measures. For ANOVA, the data were taken from three preoperative and three postoperative sessions.

For each sensorimotor task, the data are presented as a mean \pm SEM For each of the 12 sensorimotor measures, a $z$ score was calculated to standardize performance relative to the entire sample of rats. A mean $z$ score was then computed for each rat across the 12 measures, sepa-

Table 2. Omnibus ANOVA: age $\times$ pre/post $\times$ drug $\times$ session

\begin{tabular}{|c|c|c|c|c|c|c|c|}
\hline \multirow[b]{2}{*}{ Effect } & \multirow[b]{2}{*}{$\begin{array}{l}\text { Spatial } \\
\text { alternation }\end{array}$} & \multicolumn{6}{|c|}{ Place discrimination } \\
\hline & & $\begin{array}{l}\text { Swim } \\
\text { time }\end{array}$ & $\begin{array}{l}\text { Swim } \\
\text { distance }\end{array}$ & $\begin{array}{l}\text { Heading } \\
\text { angle }\end{array}$ & $\begin{array}{l}\text { Quadrant } \\
\text { time }\end{array}$ & $\begin{array}{l}\text { Annulus } \\
40 \text { time }\end{array}$ & $\begin{array}{l}\text { Number of } \\
\text { crossings }\end{array}$ \\
\hline Age & $*$ & $*$ & & & $*$ & $*$ & $*$ \\
\hline Agc $\times$ drug & $*$ & & $*$ & & & & \\
\hline Pre/post & $*$ & * & * & $\dagger$ & $*$ & * & * \\
\hline Age $\times$ pre $/$ post & $*$ & $\dagger$ & & & $\dagger$ & $*$ & * \\
\hline Age $\times$ pre $/$ post $\times$ drug & $*$ & & & & & & \\
\hline
\end{tabular}


Table 3. Focused ANOVA: 23MO rats, pre/post $\times$ drug $\times$ session

\begin{tabular}{|c|c|c|c|c|c|c|c|}
\hline \multirow[b]{2}{*}{ Effect } & \multirow{2}{*}{$\begin{array}{l}\text { Spatial } \\
\text { alterna- } \\
\text { tion }\end{array}$} & \multicolumn{6}{|c|}{ Place discrimination } \\
\hline & & Swim time & $\begin{array}{l}\text { Swim } \\
\text { distance }\end{array}$ & $\begin{array}{l}\text { Heading } \\
\text { angle }\end{array}$ & $\begin{array}{l}\text { Quadrant } \\
\text { time }\end{array}$ & $\begin{array}{l}\text { Annulus } \\
40 \text { time }\end{array}$ & $\begin{array}{l}\text { Number of } \\
\text { crossings }\end{array}$ \\
\hline $\begin{array}{l}\text { Pre/post } \\
\times \text { drug }\end{array}$ & $\dagger$ & & $\dagger$ & $\dagger$ & & & \\
\hline Pre/post & & * & * & * & $\dagger$ & * & * \\
\hline \& SME & $+\mathrm{CON}$ & $\dagger \mathrm{CON}$ & & & & & \\
\hline & & $\dagger$ NGF40 & *NGF40 & $\dagger$ NGF40 & * NGF40 & ${ }^{*}$ NGF40 & * NGF40 \\
\hline & & $\dagger$ NGF160 & * NGF160 & $\dagger$ NGF160 & & & $\dagger$ NGF160 \\
\hline Session & * & $*$ & * & & & * & \\
\hline
\end{tabular}

rately for preoperative and postoperative performance. Positive $z$ scores indicate better than average performance, negative $z$ scores indicate worse than average performance.

The experimental design was nonorthogonal (i.e., for $4 \mathrm{MO}$ rats, only CON and NGF40 groups were used; for 23MO rats, CON, NGF40, and NGF160 groups were used). Thus, to fully appreciate the obtained results, two strategies for analysis were used. First, an omnibus ANOVA was conducted in which the old rats given NGF40 and NGF160 were combined to form a single drug group. This mixed-model ANOVA was a $2(\mathrm{CON}$ vs drug) $\times 2(4 \mathrm{MO}$ vs $23 \mathrm{MO}) \times 2$ (preoperative vs postoperative) $\times 3$ or 4 (sessions). The results of the omnibus ANOVA are presented in Table 2 .

Two focused ANOVAs were also conducted to analyze the drug effects for $4 \mathrm{MO}$ and $23 \mathrm{MO}$ rats separately. This analysis was justified by the presence of several interactions between age and drug (i.e., spatial alternation), between age and pre/post testing (i.e., all but heading angle), and a three-way interaction age $\times$ drug $\times$ pre/post testing (i.e., spatial alternation). For the $4 \mathrm{MO}$ rats, the focused ANOVA was a 2 (CON vs NGF40) $\times 2$ (pre vs post) $\times 3$ or 4 (sessions) mixed-model ANOVA. For the $23 \mathrm{MO}$, the focused ANOVA was a 3 (CON, NGF40, NGF160) $\times 2$ (pre vs post) $\times 3$ or 4 (sessions) mixed-model ANOVA. These focused ANOVAs provide partially redundant tests of the corresponding effects in the omnibus ANOVA. The results of the focused ANOVA are presented in Tables 3 and 4 (23MO and 4MO rats, respectively).

The data from $4 \mathrm{MO}-\mathrm{CON}$ provided the baseline performance for al rats. An aging effect is indicated by a difference between $23 \mathrm{MO}$ and $4 \mathrm{MO}$. An $N G F$ effect is indicated by a difference between CON and NGF rats. In $23 \mathrm{MO}$, an effect of NGF was assessed by two tests. The first was a group $\times$ pre/post interaction followed by post hoc tests to assess the difference in postoperative performance between $23 \mathrm{MO}-\mathrm{NGF}$ and $23 \mathrm{MO}-\mathrm{CON}$. The second was a one-way ANOVA comparing preoperative and postoperative performance in each group separately. An NGF effect was indicated by the difference in the magnitude of the pre/ post changes for the NGF groups as compared to the control group. A dose effect was indicated by a difference between NGF40 and NGF160.

\section{Results}

$N G F$ delivery

In all cases, the osmotic minipump functioned normally. When removed from the brain, the inner reservoir of every pump was collapsed, and the volume was less than $50 \mu \mathrm{l}$, a quarter of the full volume, indicating that the solution was delivered. The cannula tubing was clear, and the tip of the cannula was in the lateral ventricle. Two rats were excluded from the data analysis. In one $23 \mathrm{MO}-\mathrm{CON}$ rat, an infection was close to the site of the infusion. In one 23MO-NGF160 rat, the pump was disconnected from the ventricular cannula. The only other complications occurred in the 23MO-NGF160 group, which had two rats with a localized inflammation around the ventricular infusion site. These rats remained in the experiment because the inflammation was restricted and their behavior was no different from other rats in their group.

Quantitative bioassay performed with the residual human NGF in the pumps confirmed that the trophic factor was bioactive throughout the treatment period (V. E. Koliatsos, J. W. Winslow, and L. E. Burton, unpublished observations).

\section{Spatial delayed alternation in the $T$ maze}

The statistical results are summarized in Tables 2-4.

Preoperative performance. Both $4 \mathrm{MO}$ groups learned quickly

Table 4. Focused ANOVA: 4MO rats, pre/post $\times$ drug $\times$ session

\begin{tabular}{|c|c|c|c|c|c|c|c|}
\hline \multirow[b]{2}{*}{ Effect } & \multirow{2}{*}{$\begin{array}{l}\text { Spatial } \\
\text { alterna- } \\
\text { tion }\end{array}$} & \multicolumn{6}{|c|}{ Place discrimination } \\
\hline & & $\begin{array}{l}\text { Swim } \\
\text { time }\end{array}$ & $\begin{array}{l}\text { Swim } \\
\text { distance }\end{array}$ & $\begin{array}{l}\text { Heading } \\
\text { angle }\end{array}$ & $\begin{array}{l}\text { Quadrant } \\
\text { time }\end{array}$ & $\begin{array}{l}\text { Annulus } \\
40 \text { time }\end{array}$ & $\begin{array}{l}\text { Number of } \\
\text { crossings }\end{array}$ \\
\hline $\begin{array}{l}\text { Pre/post } \\
\times \text { drug }\end{array}$ & $*$ & & & & & & \\
\hline Pre/post & $*$ & $*$ & $*$ & & $*$ & * & $*$ \\
\hline \& SME & $\begin{array}{l}+\mathrm{CON} \\
{ }^{*} \mathrm{NGF} 40\end{array}$ & $\begin{array}{l}* \mathrm{CON} \\
{ }^{*} \mathrm{NGF} 40\end{array}$ & $\begin{array}{l}* \mathrm{CON} \\
{ }^{*} \mathrm{NGF} 40\end{array}$ & & $\begin{array}{l}+\mathrm{CON} \\
+\mathrm{NGF} 40\end{array}$ & $\begin{array}{l}\dagger \mathrm{CON} \\
\dagger \mathrm{NGF} 40\end{array}$ & $\begin{array}{l}{ }^{*} \mathrm{CON} \\
{ }^{*} \mathrm{NGF} 40\end{array}$ \\
\hline Session & * & $*$ & * & & $*$ & * & * \\
\hline
\end{tabular}

${ }^{*} p<0.01$.

$\dagger p<0.05$.

SME, simple main effect. 


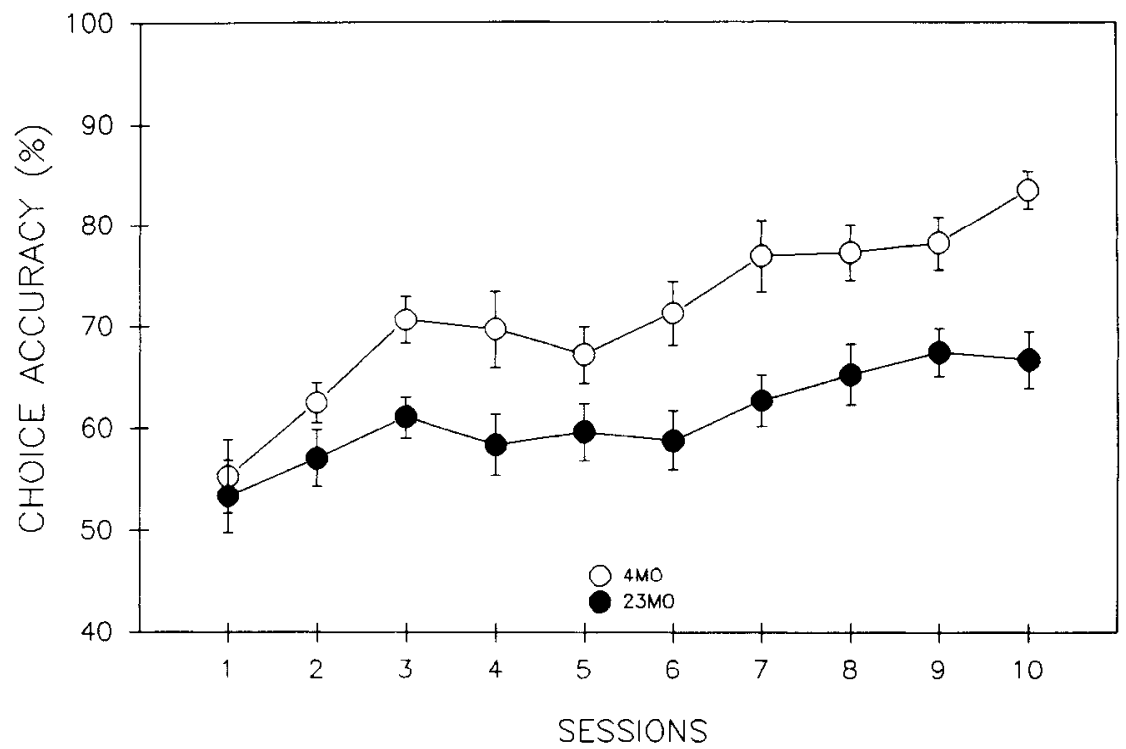

Figure 1. Spatial alternation, acquisition. The preoperative acquisition of the task was slower in $23 \mathrm{MO}$ rats as compared to $4 \mathrm{MO}$ rats. The mean choice accuracy of the $4 \mathrm{MO}$ group $(O)$ and $23 \mathrm{MO}(0)$ is presented during 10 preoperative blocks of 20 trials. Error bars indicate SEM. and reached asymptotic performance by session 7 . Choice accuracy improved during testing (two-way ANOVA, five groups $\times 10$ preoperative sessions; session effect, $F 9,315=7.7, p<$ 0.001 ). During the last four sessions (sessions 7-10), the mean choice accuracy ranged from $76 \pm 3 \%$ to $82 \pm 3 \%$ (Fig. 1).

Aging impaired performance (see age effect in Table 2). Although choice accuracy improved during testing, the magnitude of this improvement was not as great in $23 \mathrm{MO}$ rats as in $4 \mathrm{MO}$ rats (group $\times 10$ sessions interaction, $F 36,315=2.0, p<0.001$ ). During sessions $7-10$, the mean choice accuracy of all three $23 \mathrm{MO}$ groups ranged from $58 \pm 3 \%$ to $68 \pm 4 \%$. Choice accuracy in the $23 \mathrm{MO}$ groups was lower than in both $4 \mathrm{MO}$ groups $(p<0.001)$. Groups of the same age were not significantly different $(p s>0.1)$.

Postoperative performance. $4 \mathrm{MO}-\mathrm{CON}$ rats had a slight decrease in choice accuracy from the preoperative level, with a mean choice accuracy of $75 \pm 3 \%$ (Tables 3 and 4 , simple main effect; \pm SEM).
Aging impaired performance. The choice accuracy of $23 \mathrm{MO}$ CON rats significantly decreased to $51 \pm 3 \%$ as compared with preoperative performance (Table 3 ).

NGF in aged rats (Fig. 2) in both doses reduced the magnitude of age-related impairments in choice accuracy (drug $\times$ pre/post interaction). 23MO-NGF40 and 23MO-NGF160 had a mean choice accuracy not different from their preoperative levels (indicated by SEM), and greater than the choice accuracy of $23 \mathrm{MO}$ CON rats $(p<0.05)$. Choice accuracy of $23 \mathrm{MO}-\mathrm{NGF} 40$ was not different from that of $23 \mathrm{MO}-\mathrm{NGF} 160(p>0.1)$.

NGF in young rats decreased choice accuracy to $54 \pm 3 \%$ for 4MO-NGF40. Although choice accuracy decreased in both $4 \mathrm{MO}$ groups, the magnitude of this decrease was significantly greater in $4 \mathrm{MO}-\mathrm{NGF} 40$ rats than in the $4 \mathrm{MO}-\mathrm{CON}$ rats (pre/post $\times$ drug interaction, Table 4). Choice accuracy of $4 \mathrm{MO}-\mathrm{NGF} 40$ was significantly lower than that of $4 \mathrm{MO}-\mathrm{CON}(p<0.001)$.

Figure 3 presents the percentage of rats in each group with postoperative performance defined as improved, impaired, or

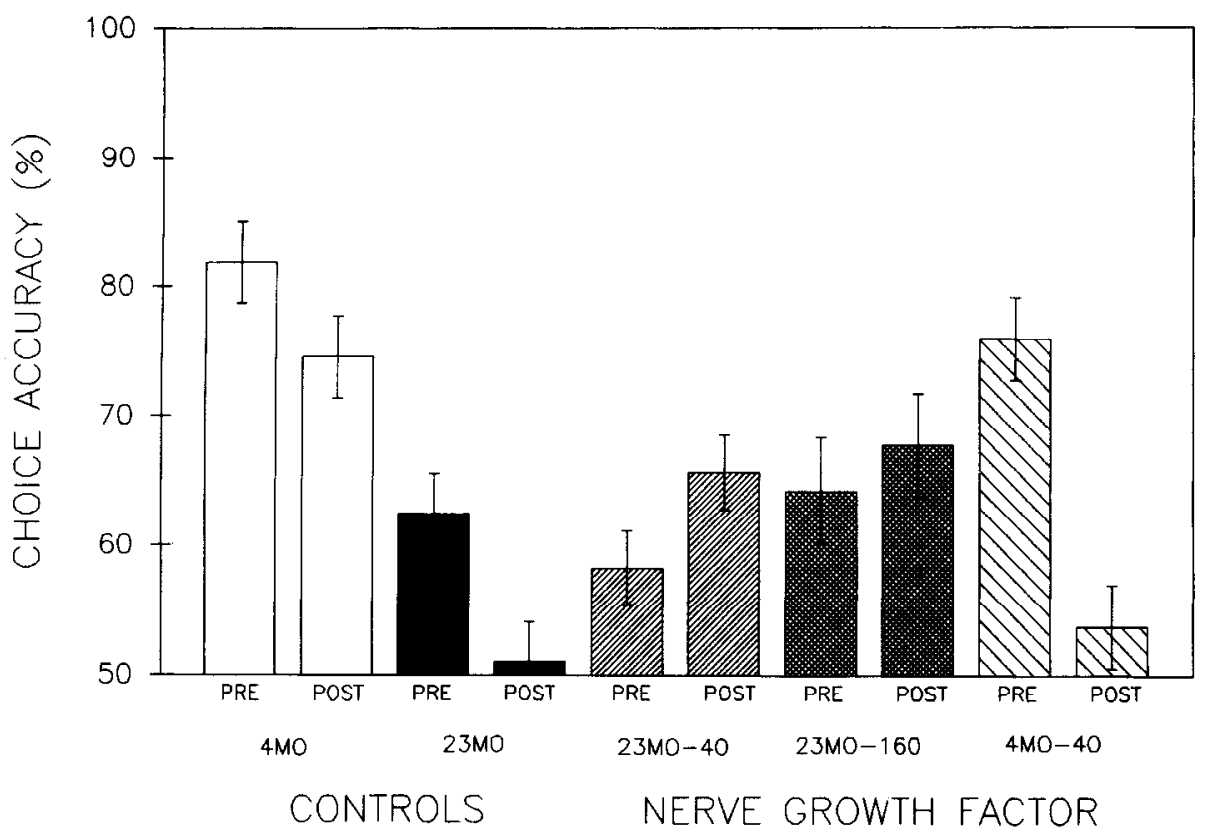

Figure 2. Spatial alternation, a comparison of preoperative and postoperative performance. For each group, the mean from preoperative ( $P R E)$ performance and postoperative (POST) performance is presented to the left and right, respectively, of each pair of histograms. The young and old control groups are presented in the first two histogram pairs, respectively. The three NGF groups are presented in the other three histogram pairs. The top of the histogram indicates the mean scorc of the group. Error bars indicate SEM. 
Figure 3. Spatial alternation, the percentage of rats in each group that were improved, unchanged, or impaired in postoperative performance as compared to preoperative performance. For each of the five groups, the height of the were improved (left bars), the same (middle bars), and impaired (right bars). bar indicates the percentage of rats that

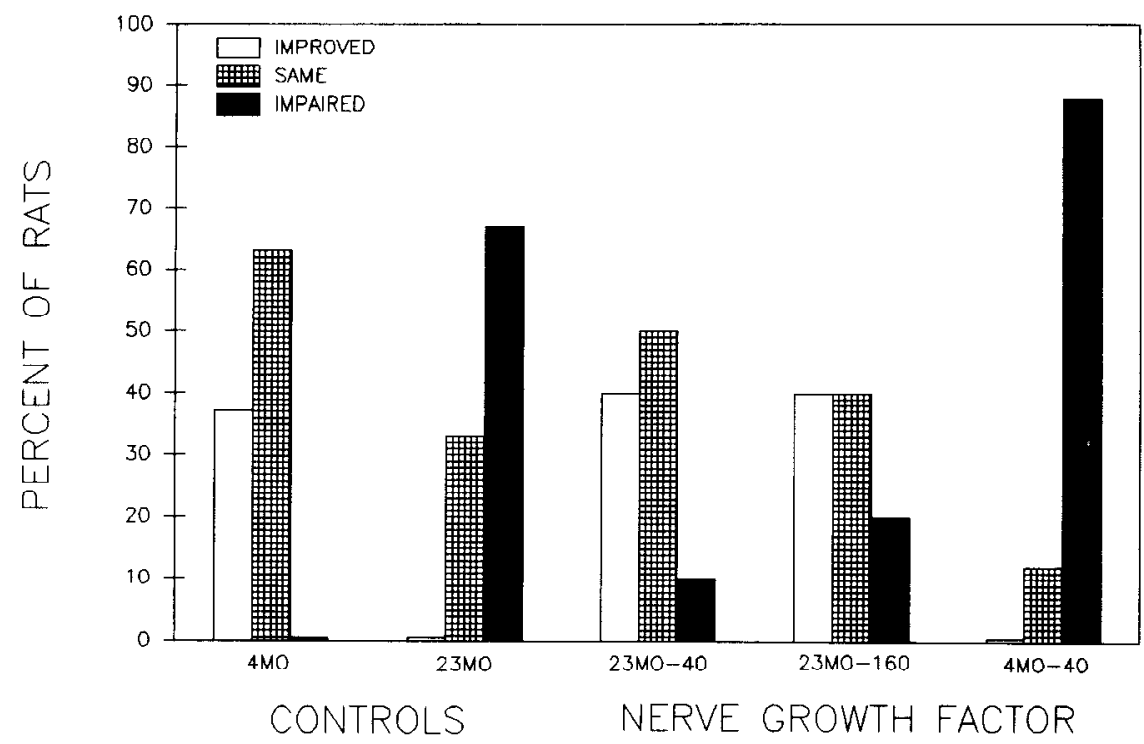

the same (see Data analysis, above, for operational definitions). None of the $4 \mathrm{MO}-\mathrm{CON}$ rats were impaired in postoperative performance, and $37 \%$ were improved. Aging impaired choice accuracy; in the $23 \mathrm{MO}$-CON group, $67 \%$ were impaired and none were improved. NGF in old rats improved choice accuracy; in 23MO-NGF40 and in 23MO-NGF160 only $10 \%$ and $20 \%$, respectively, were impaired, and $40 \%$ were improved. NGF in young rats impaired choice accuracy in 4MO-NGF40; $88 \%$ were impaired and none were improved.

\section{Place discrimination in water maze}

The mean $( \pm$ SEM $)$ pre- and postoperative performances for all measures are presented in Figure 4. Statistical results are summarized in Tables 2-4.

Preoperative performance. For both $4 \mathrm{MO}$ groups, performance improved substantially during the first three sessions for all measures except heading angle (sessions effect, $p<0.01$ ). During the last session of platform trials, the mean swim time ranged from $11 \pm 4 \mathrm{sec}$ to $12 \pm 1 \mathrm{sec}$, the mean distance from $314 \pm 89 \mathrm{~cm}$ to $333 \pm 57 \mathrm{~cm}$, and the mean angle from $36 \pm$ $7^{\circ}$ to $43 \pm 2^{\circ}$. During the last probe trial, the mean correct quadrant time ranged from $33 \pm 4 \%$ to $40 \pm 5 \%$, the mean annulus- 40 time from $42 \pm 6 \%$ to $47 \pm 6 \%$, and the mean number of crossings from $0.6 \pm 0.1$ to $0.7 \pm 0.2$.

Aging impaired performance. Although the majority of measures improved during testing, the magnitude of this improvement was not as great in $23 \mathrm{MO}$ rats as in $4 \mathrm{MO}$ rats (age $\times$ pre/ post interactions for all measures except heading angle). For the last session of platform trials, the $23 \mathrm{MO}$ groups had worse performance than the $4 \mathrm{MO}$ groups on four measures, and the mean score ranges were: for swim time, from $24 \pm 3 \mathrm{sec}$ to $32 \pm 5$ sec; quadrant time, from $19 \pm 3 \%$ to $22 \pm 3 \%$; annulus- 40 time, from $22 \pm 3 \%$ to $24 \pm 4 \%$; and number of crossings, from 0.2 to 0.1 . A reliable aging effect was present in four measures (Table $2)$. Groups at the same age performed similarly $(p>0.1)$.

Postoperative performance. The performance of $4 \mathrm{MO}-\mathrm{CON}$ rats continued to improve. This improvement was significant in all measures except heading angle (Table 4). During the last session of platform trials, the mean scores were swim time, 8 $\pm 3 \mathrm{sec}$; distance, $238 \pm 53 \mathrm{~cm}$; angle, $43 \pm 7^{\circ}$. During the last probe trial, the mean scores were correct quadrant time, $55 \pm$ $7 \%$; annulus-40 time, $60 \pm 8 \%$; number of crossings, $0.9 \pm 0.2$.

Aging attenuated the improvement in performance. $23 \mathrm{MO}$ CON performed worse than $4 \mathrm{MO}-\mathrm{CON}$ on all measures except swim time $(p<0.001)$. For the last session of platform trials, mean scores for $23 \mathrm{MO}-\mathrm{CON}$ rats were for swim time, $23 \pm 3$ sec; distance, $457 \pm 90 \mathrm{~cm}$; and heading angle, $46 \pm 5^{\circ}$. For probe trials, the mean scores were correct quadrant time, $22 \pm$ $4 \%$; annulus-40 time, $24 \pm 5 \%$; and number of crossings, 0.1 \pm 0.1 .

NGF in old rats partially reversed the effect of aging and improved performance. This effect was significant in swim distance and in heading angle as indicated by pre/post $\times$ drug interactions (Table 3). The comparison between postoperative and preoperative performance for each group (Table 3, SEM) showed that $23 \mathrm{MO}-\mathrm{CON}$ had a significant improvement in only one measure (swim time), whereas $23 \mathrm{MO}-\mathrm{NGF} 40$ had a significant improvement in all measures, and 23MO-NGF160 had a significant improvement in all but two measures (quadrant time, annulus-40 time).

NGF in young rats did not affect performance in any of the measures (pre/post $\times$ drug interaction).

\section{Sensorimotor skills}

Preoperative performance. Few rats fell from the $6 \mathrm{~cm}$ bridge or escaped from the round bridge. These measures had no variance in some groups, and therefore were excluded from analysis.

Both 4MO groups performed all tasks well. The mean $z$ score for both groups was $0.5 \pm 0.1$.

Aging impaired performance. Aged rats had a significant impairment in all tasks except initiation of walking and wire suspension $(0.05<p<0.01)$. The ability to stay on the narrow flat bridges and turn in an alley varied widely as reflected by greater standard errors (Table 5). The mean $z$ score for the $23 \mathrm{MO}$ groups ranged from $-0.1 \pm 0.2$ to $0.3 \pm 0.2$.

Postoperative performance. $4 \mathrm{MO}-\mathrm{CON}$ rats continued to perform well with a mean $z$ score of $0.6 \pm 0.2$ (Fig. 5).

Aging impaired performance. 23MO-CON rats performed significantly worse than $4 \mathrm{MO}-\mathrm{CON}$ rats on the majority of tasks $(0.01<p<0.05)$, and their mean $z$ score of $-0.3 \pm 0.1$ was significantly worse than the mean $z$ score for $4 \mathrm{MO}-\mathrm{CON}(p<$ 

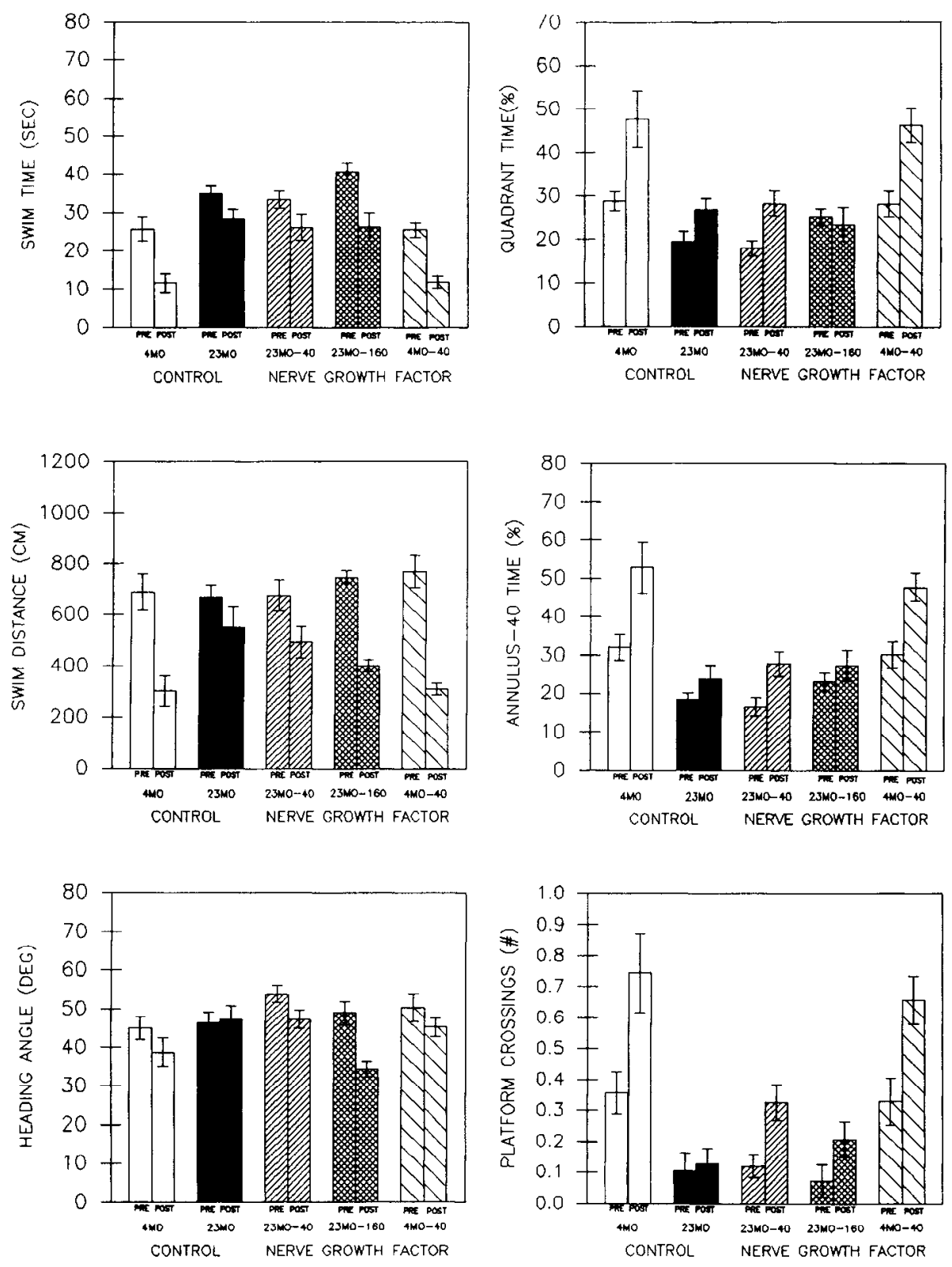

Figure 4. Place discrimination in water maze, a comparison of preoperative and postoperative performance. The left column presents data from platform trials: top, swim time; middle, swim distancc; bottom, heading anglc. The right column presents data from probe trials: top, quadrant time; middle, annulus 40 time; bottom, platform crossings. For each group, the mean from preoperative $(P R E)$ performance and postoperative (POST) performance is presented in the left and right side of each pair of histograms, respectively. The young and old control groups are presented in the first two histogram pairs, respectively. The three NGF groups are presented in the other three histogram pairs. The top of the histogram indicates the mean score of the group. Error bars indicate SEM.

0.01). Postoperative scores were similar to preoperative in $23 \mathrm{MO}-\mathrm{CON}$.

NGF in old rats did not affect performance. 23MO-NGF40 and 23MO-NGF160 had mean $z$ scores similar to those for 23MO-CON (Fig. 5).

NGF in young rats did not affect performance. 4MO-NGF40 had mean $z$ scores similar to that for $4 \mathrm{MO}-\mathrm{CON}$ (Fig. 5).

\section{Discussion}

The present study demonstrates that human recombinant NGF can have profound behavioral effects in aged and young rats. First, NGF reduced the magnitude of age-related cognitive impairments in recent memory as assessed by spatial alternation in the $\mathrm{T}$ maze, an effect suggesting that NGF may reduce agerelated impairments in many different cognitive domains that depend on the septohippocampal cholinergic system. Second, NGF ameliorated age-related impairments in spatial reference memory as assessed by place discrimination in the water maze.
Third, sensorimotor aspects of performance were not affected by NGF treatment, a result suggesting that nonmnemonic factors did not contribute to the beneficial effects of NGF on memory in aged rats. Fourth, both doses of NGF were equally effective, indicating that NGF may be beneficial in a wide range of doses. Fifth, in young adult rats, NGF impaired recent memory but not place discrimination. Finally, a new form of NGF, human NGF, produced similar effects to those produced by mouse NGF, indicating that many kinds of NGF may improve cognitive function in aged rats, and that human recombinant NGF may have applicability in humans.

Previous experiments assessing the effects of NGF on memory of aged rats tested only reference memory (Fischer et al., 1987, 1991 a; Williams et al., 1991) and did not include recent memory tasks. Recent memory depends on the integrity of the basal forebrain cholinergic system (Olton and Wenk, 1987; Givens and Olton. 1990; Markowska et al., 1990a,b; Olton et al., 199 la,b; Olton and Markowska, 1992), and is impaired in aging (de- 
Table 5. Sensorimotor tasks

\begin{tabular}{|c|c|c|c|c|c|c|c|c|c|c|c|c|c|c|}
\hline \multirow[b]{2}{*}{ Group } & \multirow{2}{*}{\multicolumn{2}{|c|}{ 4MO-CON }} & \multirow{2}{*}{\multicolumn{2}{|c|}{$23 \mathrm{MO}-\mathrm{CON}$}} & \multirow{2}{*}{\multicolumn{2}{|c|}{ 23MO-NGF40 }} & \multirow{2}{*}{\multicolumn{2}{|c|}{ 23MO-NGF160 }} & \multirow{2}{*}{\multicolumn{2}{|c|}{ 4MO-NGF40 }} & \multirow{2}{*}{$\begin{array}{l}\text { Age } \\
\text { CON, } \\
4 \mathrm{MO} \text { vs } \\
23 \mathrm{MO}\end{array}$} & \multicolumn{2}{|l|}{ NGF40 } & \multirow{2}{*}{$\begin{array}{l}\text { NGF160 } \\
23 \mathrm{MO}, \\
\text { NGF160 } \\
\text { vs CON }\end{array}$} \\
\hline & & & & & & & & & & & & $\begin{array}{l}\text { 4MO, } \\
\text { NGF40 } \\
\text { vs CON }\end{array}$ & $\begin{array}{l}23 \mathrm{MO}, \\
\text { NGF40 } \\
\text { vs CON }\end{array}$ & \\
\hline \multirow[t]{2}{*}{ Walking initiation } & 8 & 1 & 12 & 2 & 11 & 3 & 9 & 2 & 9 & 2 & & & & \\
\hline & 10 & 2 & 12 & 2 & 25 & 10 & 9 & 1 & 13 & 2 & & & & \\
\hline \multirow[t]{2}{*}{ Turning in an alley } & 10 & 2 & 34 & 11 & 31 & 12 & 37 & 13 & 12 & 4 & $*$ & & & \\
\hline & 10 & 2 & 47 & 11 & 23 & 6 & 15 & 4 & 7 & 1 & $*$ & & $*$ & * \\
\hline \multirow[t]{2}{*}{ Inclined screen } & 24 & 4 & 25 & 2 & 28 & 10 & 15 & 2 & 12 & 2 & $*$ & & & \\
\hline & 16 & 2 & 15 & 6 & 28 & 11 & 11 & 3 & 11 & 2 & $*$ & & & \\
\hline \multirow[t]{2}{*}{ Wire suspension } & 4 & 1 & 4 & 1 & 2 & 0 & 6 & 1 & 9 & 2 & & & & \\
\hline & 8 & 6 & 8 & 3 & 2 & 1 & 7 & 3 & 3 & 1 & & & & \\
\hline \multicolumn{15}{|l|}{ Bridges } \\
\hline \multicolumn{15}{|l|}{ Escape } \\
\hline \multirow[t]{2}{*}{$6 \mathrm{~cm}$ flat } & 27 & 7 & 64 & 11 & 60 & 10 & 32 & 6 & 39 & 12 & $* *$ & & & \\
\hline & 19 & 5 & 65 & 14 & 57 & 14 & 28 & 5 & 47 & 15 & ** & & & \\
\hline \multirow[t]{2}{*}{$4 \mathrm{~cm}$ flat } & 34 & 9 & 83 & 6 & 68 & 10 & 48 & 13 & 46 & 11 & $*$ & & & \\
\hline & 34 & 9 & 73 & 12 & 57 & 13 & 49 & 17 & 46 & 16 & * & & & \\
\hline \multirow[t]{2}{*}{$2 \mathrm{~cm}$ fiat } & 42 & 9 & 120 & 0 & 117 & 3 & 98 & 12 & 54 & 11 & $* *$ & & & \\
\hline & 38 & 8 & 120 & 0 & 111 & 8 & 120 & 0 & 52 & 16 & $* *$ & & & \\
\hline \multirow[t]{2}{*}{$2 \mathrm{~cm}$ round } & 120 & 0 & 120 & 0 & 120 & 0 & 120 & 0 & 117 & 3 & & & & \\
\hline & 120 & 0 & 120 & 0 & 120 & 0 & 120 & 0 & 120 & 0 & & & & \\
\hline \multicolumn{15}{|l|}{ Fall } \\
\hline \multirow[t]{2}{*}{$6 \mathrm{~cm}$ flat } & 120 & 0 & 106 & 6 & 95 & 6 & 107 & 7 & 120 & 0 & $*$ & & & \\
\hline & 120 & 0 & 120 & 0 & 120 & 0 & 120 & 0 & 120 & 0 & & & & \\
\hline \multirow[t]{2}{*}{$4 \mathrm{~cm}$ flat } & 120 & 0 & 95 & 10 & 94 & 8 & 96 & 10 & 116 & 4 & $*$ & & & \\
\hline & 120 & 0 & 88 & 13 & 118 & 2 & 40 & 4 & 120 & 0 & $*$ & & $*$ & * \\
\hline \multirow[t]{2}{*}{$2 \mathrm{~cm}$ flat } & 114 & 5 & 39 & 5 & 31 & 6 & 47 & 14 & 120 & 0 & $* *$ & & & \\
\hline & 120 & 0 & 37 & 12 & 36 & 10 & 40 & 4 & 120 & 0 & $* *$ & & & \\
\hline \multirow[t]{2}{*}{$2 \mathrm{~cm}$ round } & 15 & 1 & 7 & 2 & 5 & 1 & 6 & 1 & 30 & 8 & $*$ & $*$ & & \\
\hline & 24 & 4 & 8 & 2 & 3 & 1 & 5 & 1 & 11 & 3 & * & * & & \\
\hline
\end{tabular}

The value in the upper row indicates preoperative latencies (sec); the lower row indicates postoperative latencies (sec). $M$, mean ${ }^{*} p<0.05$.

** $p<0.01$.

Figure 5. Sensorimotor tasks, a comparison of preoperative and postoperative performance using the same format as for spatial alternation in Figure 2 . The mean $z$ score, which indicates the relative standing of each group, is presented in the same format as in Figure 2.

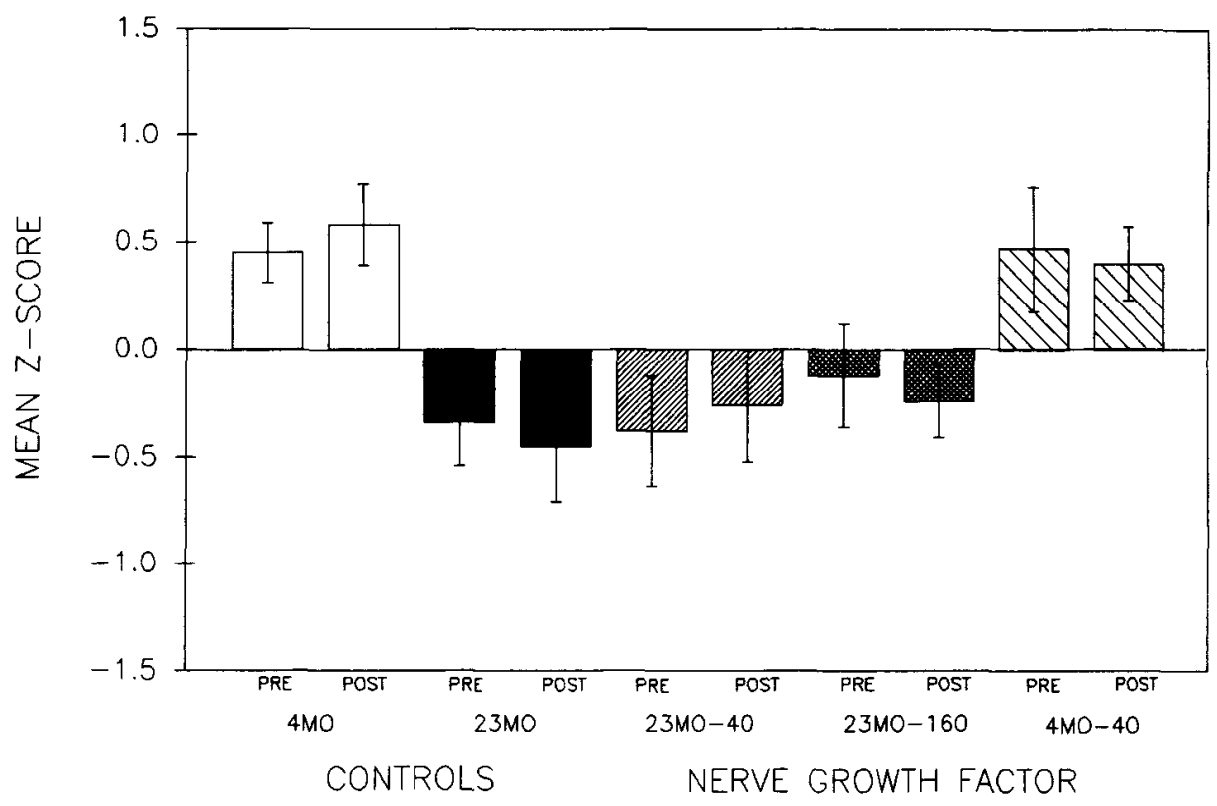


Toledo-Morell et al., 1988; Aggleton et al., 1989). In the present study, recent memory in aged rats was improved by human NGF; compared to preoperative performance, most aged control rats were impaired posloperatively and none improved, while most NGF-treated aged rats either improved or did not change. This beneficial effect of human NGF on the recent memory of aged rats extends the behavioral domains in which human NGF is effective, suggesting the generality of the effect across various types of memory.

Spatial reference memory as assessed by performance in place discrimination also improved in aged rats following infusion of human NGF. These beneficial effects were very noticeable in two mcasures (swim distance and heading angle), and were modest in other measures. A comparison of the preoperative and postoperative performance for each group of rats indicated a difference between 23MO-NGF and 23MO-CON rats. Whereas the difference in preoperative and postoperative performance for $23 \mathrm{MO}-\mathrm{CON}$ rats was significant in only one measure, this difference for 23MO-NGF40 and 23MO-NGF160 was significant in five and four measures, respectively. Therefore, the effect of human NGF on place discrimination was evident in most behavioral measures. Mouse NGF in aged Sprague--Dawley rats produced similar behavioral improvements in place discrimination as measured by swim time, swim distance, and number of platform crossings (Fischer et al., 1987, 1991a). Taken together, the present results indicate that human NGF may reduce many different age-related cognitive impairments that depend on the basal forebrain cholinergic system.

In the present study, both NGF doses (40 $\mu \mathrm{g}$ and $160 \mu \mathrm{g}$ ) produced behavioral changes in the aged rats. In some variables, the higher dose produced a greater improvement than the lower dose, but this trend did not reach statistical significance.

Sensorimotor impairments in the $23 \mathrm{MO}$ rats were generally unaffected by NGF. Most importantly, all three 23MO groups had similar scores, and the postoperative performance (as expressed by the mean $z$ score across all sensorimotor tasks) was similar to the preoperative performance for all of the groups (Fig. 5). Consequently, the improved performance produced by NGF in the aged rats in spatial alternation and place discrimination is most likely due to changes in cognitive abilities rather than changes in sensory input or motor control.

Previous studies on the effect of NGF on the motor aspects of performance have shown conflicting results. NGF reduced the number of avoidance responses in a shock-motivated brightness discrimination (Williams et al., 1991). Conversely, NGF prevented the progressive impairment of swim speed of aged rats in spatial discrimination in the water maze (Fischer et al., 1991a). However, the difference in swim speed between the control and NGF groups disappeared when the escape platform was made visible. Consequently, the differences between groups in swim speed in the spatial version of the task may not reflect differences in swimming ability, complicating the interpretation of the NGF effect on sensorimotor abilities.

In the majority of young rats, NGF impaired choice accuracy in the recent memory task. The neural basis of such an effect remains unclear. It may be due to hypertrophy of cholinergic neurons in the basal forebrain where measurable cholinergic cellular atrophy has not yet evolved (Fischer et al., 1991a). Alternatively, the induction of undesirable sprouting of intact cholinergic axons may modify activity in the BFCS, and contribute to behavioral impairment (Crutcher and Saffran, 1990; Saffran and Crutcher, 1990). Because NGF in young rats altered recent memory but not place discrimination, neural systems contributing to these behaviors may have different sensitivity to NGF.

Finally, these experiments used human recombinant NGF. Information about human NGF is essential to assess its potential use in clinical trials, particularly in Alzheimer's disease, which is associated with a consistent and early dysfunction of neurons in the BFCS (Phelps et al., 1989). In previous studies, human recombinant $\mathrm{NGF}$ reduced the extent of neuropathology induced by axotomy in BFCS neurons (Tuszynski et al., 1990; Koliatsos et al., 1991). In the present study, human recombinant NGF improved memory in aged rats. However, the present study also raises the issue of potential detrimental effects that NGF may exert in young normal subjects. Additional studies on the behavioral effects of NGF on young animals may provide information about mechanisms of behavioral impairments from NGF treatment, which may or may not be associated with the changes induced in the BFCS.

\section{References}

Aggleton JP, Blindt HS, Candy JM (1989) Working memory in aged rats. Behav Neurosci 103:975-983.

Altavista MC, Bentivoglio AR, Crociani P, Rossi P, Albanses A (1988) Age-dependent loss of cholinergic neurons in the basal ganglia of rats. Brain Res 455:177-181.

Altavista MC, Rossi P, Bentivoglio AR, Crociani P, Albanses A (1990) Aging is associated with a diffuse impairment of forebrain cholinergic neurons. Brain Res 508:51-59.

Bartus RT, Dean RL, Goas JA, Lippa AS (1980) Age-related changes in passive avoidance retention: modulation with dietary choline. Science 209:301-303.

Bartus RT, Dean RL, Beer F, Lippa AS (1982) The cholinergic hypothesis of geriatric memory dysfunction. Science 217:408-417.

Biegon A, Greenberger V, Segal M (1986) Quantitative histochemistry of brain acetylcholinesterase and learning rate in the aged rat. Neurobiol Aging 7:215-217.

Crutcher KA, Saffran BN (1990) Trophomorphism: a unifying hypothesis to explain neuronal rearrangements. Soc Neurosci Abstr 16: 993.

Crutcher KA, Weingartner K (1991) Hippocampal NGF levels are not reduced in the aged Fischer 344 rat. Neurobiol Aging 12:449-454.

Decker MW, Gallagher M (1987) Scopolamine-disruption of radial arm maze performance: modification by noradrenergic depletion. Brain Res 417:59-69.

Dekker AJ, Jangdon DJ, Gage FH, Thal LJ (1991) NGF increases cortical acetylcholine release in rats with lesions of the nucleus basalis. Neuroreport 2:577-580.

Dekker AJ, Gage FH, Thal LJ (1992) Delayed treatment with nerve growth factor improves acquisition of a spatial task in rats with lesions of the nucleus basalis magnocellularis: evaluation of the involvement of different neurotransmitter systems. Neuroscience 48:111-119.

deToledo-Morell L, Geinisman Y, Morrell F (1988) Individual differences in hippocampal synaptic plasticity as a function of aging: behavioral, electrophysiological and morphological evidence. In: Neural plasticity: a lifespan approach, pp 283-328. New York: Liss.

Fischer W, Wictorin K, Bjorklund A, Williams LR, Varon S, Gage FH (1987) Amelioration of cholinergic neuron atrophy and spatial memory impairment in aged rats by nerve growth factor. Nature 329:6568.

Fischer W, Gage FH, Bjorklund A (1989) Degenerative changes in forebrain cholinergic nuclei correlate with cognitive impairments in aged rats. Eur J Neurosci 1:34-45.

Fischer W, Bjorklund A, Chen K, Gage FH (1991a) NGF improves spatial memory in aged rodents as a function of age. $J$ Neurosci 11: 1889-1906.

Fischer W, Chen KS, Gage FH, Bjorklund A (1991b) Progressive decline in spatial learning and integrity of forebrain cholinergic neurons in rats during aging. Neurobiol Aging 13:9-23.

Fleischman CA, Gustilo MC, Markowska AL, Gorman LK, Burton LE, Olton DS, Price DL, Koliatsos VE (1992) Human nerve growth factor (NGF) selectively improves spatial memory deficits in aged 
rats via stimulation of the basal forebrain cholinergic system (BFCS). Soc Neurosci Abstr 18:415.

Gage FH, Bjorklund A, Stenevi U, Dunnet SB, Kelly PAT (1984) Intrahippocampal septal grafts ameliorate learning deficits in aged rats. Science 225:533-536.

Gage FH, Armstrong DM, Williams DR, Varon S (1988a) Morphological response of axotomized septal neurons to nerve growth factor. J Comp Neurol 269:147-155.

Gage FH, Chen KS, Buzsaki G, Armstrong D (1988b) Experimental approaches to age-related cognitive impairments. Neurobiol Aging 9:645-655.

Gallagher M, Pelleymounter MA (1988) Spatial learning deficits in old rats: a model for memory declinc in the aged. Neurobiol Aging 9:549-556.

Gilad GM, Rabey JM, Tizabi Y, Gilad VH (1987) Age-dependent loss and compensatory changes of septohippocampal cholinergic neurons in two strains differing in longevity and response to stress. Brain Res 436:322.

Givens BS, Olton DS (1990) Cholinergic and GABAergic modulation of medial septal area: effect on working memory. Behav Neurosci 104:849-855.

Gnahn H, Hefti F, Heumann R, Schwab ME, Thoenen H (1983) NGF mediated increase of choline acetyltransferase (ChAT) in the neonatal rat forebrain: evidence for a physiological role of NGF in the brain? Dev Brain Res 9:45-52.

Gomez-Pinilla F, Cotman CW, Nieto-Sampedro M (1989) NGF-receptor immunoreactivity in aged rat brain. Brain Res 479:255-262.

Gorman LK, Pang K, Frick KM, Givens B, Olton DS (in press) Acetylcholine release in the hippocampus: effects of cholinergic and GABAergic compounds in the medial septal area. Neurosci Lett, in press.

Hefti $F$ (1986) Nerve growth factor promotes survival of septal cholinergic neurons after fimbria transections. J Neurosci 6:2155-2162.

Hellweg R, Fischer W, Hock W, Gage FH, Bjorklund A, Thoenen H (1990) Nerve growth factor: levels and choline acetyltransferase activity in the brain of aged rats with spatial memory impairments. Brain Res 537:123-130.

Ingram DK, London ED, Goodrick CL (1981) Age and neurochemical correlates of radial maze performance in rats. Neurobiol Aging 2:4147.

Koh S, Loy R (1988) Age-related loss of nerve growth factor sensitivity in rat basal forebrain neurons. Brain Res 440:396-401.

Koh S, Chang P, Collier TJ, Loy R (1989) Loss of NGF receptor immunoreactivity in basal forebrain neurons of aged rats: correlation with spatial memory impairment. Brain Res 498:397-404.

Koliatsos VE, Applegate MD, Knusel B, Junard EO, Burton LE, Mobley WC, Hefti FF, Price DL (1991) Recombinant human nerve growth factor prevents retrograde degeneration of axotomized basal forebrain. Exp Neurol 112:161-173.

Kromer LF (1987) Nerve growth factor treatment after brain injury prevents neuronal death. Science 235:214-216.

Luine V, Hearns M (1990) Spatial memory deficits in aged rats: contributions of the cholinergic system assessed by ChAT. Brain Res 523: 321-324.

Mandel RJ, Gage FH, Thal LJ (1989) Spatial learning in rats: correlation with cortical choline acetyltransferase and improvement with NGF following NBM damage. Exp Neurol 104:208-217.

Markowska AL, Wenk GL, Olton DS (1990a) Nucleus basalis magnocellularis and memory: differential effects of two neurotoxins. Behav Neural Biol 54:13-26.

Markowska AL, Givens B, Olton DS (1990b) Cholinergic activation of medial septal area can restore working memory in old rats and in scopolamine-treated young rats. Soc Neurosci Abstr 16:918.

Markowska AL, Caprioli A. Pang K. Olton DS (1991) Blockade of muscarinic receptors in medial septal area or nucleus basalis magnocellularis impairs spatial memory. Soc Neurosci Abstr 17:137.

Markowska AL, Long JM, Johnson CT, Olton DS (1993) Variableinterval probe test as a tool for repeated measurements of spatial memory in the water maze. Behav Neurosci 107:627-632.

Mitchell SJ, Rawlins JNP, Steward O, Olton DS (1982) Medial septal area lesions disrupt theta rhythm and cholinergic staining in medial entorhinal cortex and produce impaired radial arm maze behavior in rats. J Neurosci 2:292-302.

Mobley WC, Rutkowski JL, Tennekoon GI, Gemski J, Buchanan K, Johnston MV (1986) Nerve growth factor increases choline acetyltransferase activity in developing basal forebrain neurons. Mol Brain Res 1:53-62.

Montero CN, Hefti F (1988) Rescue of lesioned septal cholinergic neurons by nerve growth factor: specificity and requirement for chronic treatment. J Neurosci 8:2986-2999.

Morris RGM, Garrud P, Rawlins J, O'Keefe J (1982) Place navigation impaired in rats with hippocampal lesions. Nature 297:681-683.

Olton DS (1990) Dementia: animal models of the cognitive impairments following damage to the basal forebrain cholinergic system. Brain Res Bull 25:499-502.

Olton DS, Markowska AL (1992) The aging and septohippocampal system: its role in age-related memory impairments. In: Neuropsychology of memory (Squire LR, Butter N, eds), pp 378-385. New York: Guilford.

Olton DS, Wenk GL (1987) Dementia: animal models of the cognitive impairments produced by degeneration of the basal forebrain cholinergic system. In: Psychopharmacology: the third generation of progress (Meltzer HY, ed), pp 941-952. New York: Raven.

Olton DS, Givens BS, Markowska AL, Shapiro M, Golski S (1991a) Mnemonic functions of the cholinergic septohippocampal system. In: Memory: organization and locus of change (Squire LR, Weinberger NM, Lynch G, McGaugh JL, eds), pp 250-269. New York: Oxford UP.

Olton DS, Markowska AL, Voytko ML (1991b) Working memory. In: Encyclopedia of memory (Squire LR, ed), pp 635-638. New York: Macmillan.

Phelps CH, Gage FH, Growdon JH, Hefti F, Harbaugh R, Johnston MV, Khachaturian ZS, Mobley WC, Price DL, Raskind M, Simpkins J, Thal LH, Woodcock K (1989) Potential use of nerve growth factor to treat Alzhcimcr's discase. Ncurobiol Aging 10:205-207.

Price DL (1986) New perspective on Alzheimer's disease. Annu Rev Neurosci 9:489-512.

Rapp PR, Rosenberg RA, Gallagher M (1987) An evaluation of spatial information processing in aged rats. Behav Neurosci 101:3-12.

Saffran BN, Crutcher KA (1990) NGF-induced remodeling of mature uninjured axon collaterals. Brain Res 525:11-20.

Tuszynski MH, Armstrong DM, Gage FH (1990) Basal forebrain cell loss following fimbria/fornix transection. Brain Res 508:241-248.

Wenk GL, Markowska AL. Olton DS (1989) Basal forebrain lesions and memory: alteration in neurotensin, not acetylcholine, may cause amnesia. Behav Neurosci 103:1624-1628.

Will B, Hefti F (1985) Behavioral and neurochemical effects of chronic intraventricular injections of nerve growth factor in adult rats with fimbria lesions. Behav Brain Res 17:17-24.

Williams LR, Varon S, Peterson GM, Wictorin K, Fischer W, Bjorklund A, Gage FH (1986) Continuous infusion of nerve growth factor prevents basal forebrain neuronal death after fimbria fornix transection. Proc Natl Acad Sci USA 83:9231-9235.

Williams LR, Rylett RJ, Moises HC, Tang AH (1991) Exogenous NGF affects cholinergic transmitter function and Y-maze behavior in aged Fischer 344 male rats. Can J Neurol Sci 18:403-407. 